\title{
Plasticity of Presynaptic and Postsynaptic Serotonin IA Receptors in an Animal Model of Epilepsy-Associated
} Depression

\author{
Eduardo A Pineda', Julie G Hensler², Raman Sankar', Don Shin', Teresa F Burke² and Andréy M Mazarati*,', \\ 'Department of Pediatrics, David Geffen School of Medicine, University of California Los Angeles, Los Angeles, CA, USA; ${ }^{2}$ Department \\ of Pharmacology, University of Texas Health Science Center-San Antonio, San Antonio, TX, USA
}

\begin{abstract}
Depression is a common comorbidity of temporal lobe epilepsy and has highly negative impact on patients' quality of life. We previously established that pilocarpine-induced status epilepticus (SE) in rats, concurrently with chronic epilepsy leads to depressive impairments, and that the latter may stem from the dysregulation of hypothalamo-pituitary-adrenocortical (HPA) axis and/or diminished raphehippocampal serotonergic transmission. We examined possible involvement of presynaptic and postsynaptic serotonin IA (5-HTIA) receptors in epilepsy-associated depression. Based on their performance in the forced swim test (FST), post-SE animals were classified as those with moderate and severe depressive impairments. In moderately impaired rats, the activity of the HPA axis (examined using plasma corticosterone radioimmunoassay) was higher than in naive subjects, but the functional capacity of presynaptic 5-HTIA receptors (measured in raphe using autoradiography) remained unaltered. In severely depressed animals, both the activity of the HPA axis and the function of presynaptic 5-HTIA receptors were increased as compared with naive and moderately depressed rats. Pharmacological uncoupling of the HPA axis from raphe nucleus exerted antidepressant effects in severely impaired rats, but did not modify behavior in both naive and moderately depressed animals. Further, the function of postsynaptic 5-HTIA receptors was diminished in the hippocampus of post-SE rats. Pharmacological activation of postsynaptic 5-HTIA receptors improved depressive deficits in epileptic animals. We suggest that under the conditions of chronic epilepsy, excessively hyperactive HPA axis activates presynaptic 5-HTIA receptors, thus shifting the regulation of serotonin release in favor of autoinhibition. Downregulation of postsynaptic 5-HTIA receptors may further exacerbate the severity of epilepsy-associated depression.

Neuropsychopharmacology (20 II) 36, I305-1316; do: I0.1038/npp.20 I I. I8; published online 23 February 20 I I
\end{abstract}

Keywords: epilepsy; depression; comorbidity; serotonin IA receptors; dorsal raphe; hypothalamo-pituitary-adrenocortical axis

\section{INTRODUCTION}

Depression represents one of the most frequent comorbidities of temporal lobe epilepsy (TLE; Kanner, 2009a; LaFrance et al, 2008). While depression associated with epilepsy has an undeniable psychosocial aspect, it has also been recognized that this condition has neurobiological substrate (Jobe et al, 1999; Kanner, 2009a, b; Kondziella et al, 2007). In our earlier studies we established that rats that had been subjected to lithium chloride and pilocarpine status epilepticus (SE), concurrently with recurrent seizures, developed interictal depression-like impairments indicative of hopelessness and anhedonia (Mazarati et al, 2008, 2009,

*Correspondence: Dr AM Mazarati, Department of Pediatrics, Neurology Division, David Geffen School of Medicine at UCLA, Box 951752, 22-474 MDCC, Los Angeles, CA 90095-1752, USA,

Tel: + I 310206 5198, Fax: + I 3108255834 ,

E-mail: mazarati@ucla.edu

Received 3 November 2010; revised 5 January 201।; accepted 27 January 201 I
2010). Furthermore, we showed that epilepsy-associated depression may stem from the dysregulation of the hypothalamo-pituitary-adrenocortical (HPA) axis (Mazarati et al, 2009, 2010), and the diminished raphe-hippocampal serotonergic transmission (Mazarati et al, 2008). It should be noted that the HPA dysfunction (Chaouloff, 2000; Dinan, 2001; Holsboer, 1998; Kondziella et al, 2007; Plotsky et al, 1998; Yu et al, 2008) and the deficit of brain serotonergic system (Kondziella et al, 2007; Lanfumey et al, 2008; Manji et al, 2001; Mann et al, 1989) are recognized as both hallmarks and putative mechanistic factors of major depression; therefore, our experimental findings exemplify the line of thought that high incidence of depression among TLE patients is a result of common pathogenic mechanisms shared by the two disorders (Jobe, 2003; Kondziella et al, 2007).

The activity of raphe serotonergic neurons (and thus the release of serotonin from their terminals) is regulated by several extrinsic and intrinsic factors (Hokfelt et al, 1998); therefore, serotonergic dysfunction in depression may stem 
from a variety of causes. One putative mechanism involves the short-feedback autoinhibitory loop, which is driven by serotonin 1A (5-HT1A) receptors, located in the soma and the dendrites of raphe serotonergic neurons (hence also referred to as presynaptic receptors, or autoreceptors; Aghajanian et al, 1990; Lanfumey et al, 2008; Riad et al, 2000; Sprouse and Aghajanian, 1987). Activation of these receptors (eg the increase of their number and/or the enhancement of their function) would result in the diminished firing of raphe serotonergic neurons and consequently in the compromised raphe-hippocampal serotonergic transmission. Indeed, the increased binding capacity (Parsey et al, 2006) or expression (Lemonde et al, 2003) of raphe 5-HT1A receptors has been shown in patients with major depression. Alternatively, the paucity of serotonergic transmission may occur on the postsynaptic level as a result of the decreased number and/or function of postsynaptic 5-HT1A receptors (Sargent et al, 2000).

It has been suggested that the HPA axis interacts with raphe 5-HT1A receptors in a complex manner, and that impairments in this interaction may contribute to depression (Lanfumey et al, 2008). However, different reports offer conflicting results as to the effects of the HPA axis on presynaptic 5-HT1A receptors: both positive (Bellido et al, 2004; Judge et al, 2004) and negative (De Kloet et al, 1986; Lanfumey et al, 2008; Man et al, 2002) regulation of the latter by circulating glucocorticoids have been suggested. Such discrepant findings may be due to the fact that glucocorticoids may drive brain serotonergic transmission in opposite directions depending on their concentration: at low levels glucocorticoids may stimulate, while at high levels, suppress serotonergic transmission (Judge et al, 2004).

The goal of the present study was to advance our understanding of the role, which both presynaptic and postsynaptic 5-HT1A receptors have in the mechanisms of epilepsy-associated depression, and of possible regulation of these receptors by the HPA axis. First, we examined functional state and number of 5-HT1A receptors in dorsal raphe and the hippocampus of rats with chronic epilepsy and concurrent depression. Further, we analyzed whether and how changes in presynaptic and postsynaptic 5-HT1A receptors paralleled with the extent of neuroendocrine and behavioral depression-like impairments. Finally, we explored whether the blockade of effects of circulating glucocorticoids on the levels of dorsal raphe and of the hippocampus would normalize behavioral and biochemical hallmarks of epilepsy-associated depression.

\section{MATERIALS AND METHODS}

\section{Subjects}

The experiments were performed in male Wistar rats (Charles River, Wilmington, MA), 50 days old at the beginning of the study, in accordance with the policies of the National Institutes of Health.

\section{Status Epilepticus}

Animals received intraperitoneal injection of $\mathrm{LiCl}(3 \mathrm{mEq} /$ $\mathrm{kg}$; Sigma, St Louis, MO), and $24 \mathrm{~h}$ later, subcutaneous injection of pilocarpine $(40 \mathrm{mg} / \mathrm{kg}$; Sigma). SE was characterized by continuous seizures starting from 10 to $15 \mathrm{~min}$ after pilocarpine injection. Three and $8 \mathrm{~h}$ after seizure onset, rats were injected with diazepam $(10 \mathrm{mg} / \mathrm{kg})$ and phenytoin $(50 \mathrm{mg} / \mathrm{kg})$. In control animals, pilocarpine was substituted with saline. The described procedure is known to reliably induce chronic epilepsy, which shares several key features with human TLE, such as hippocampal neuronal degeneration, synaptic reorganization, and spontaneous recurrent complex partial seizures (commonly with secondary generalization). The latter develop after a 'silent' period, which lasts between several days and several weeks, and persist for the lifetime of the animal with a variable frequency (Cavalheiro et al, 2006). All experiments started 2 months after SE.

\section{Spontaneous Seizures}

In order to avoid ambiguity in the interpretation of the outcome data (D'Ambrosio et al, 2009; Dube et al, 2006; Dudek and Bertram, 2010), only behavioral seizures stage 4-5 (ie rearing and/or rearing and falling; Racine, 1972) were considered. Animals were continuously monitored for 2 weeks, and seizures were analyzed offline using digital video monitoring system (Super Circuits, Austin, TX).

In order to avoid immediate effects of spontaneous seizures on outcome measurements, all further experiments were performed upon verification that no seizures had developed for at least $6 \mathrm{~h}$ prior the test; this seizure-free period had been validated as having no bearing on chronic depressive impairments (Mazarati et al, 2008, 2009). If spontaneous seizures occurred during any test, the latter was discontinued.

\section{Forced Swim Test}

Forced swim test (FST) consisted of a single 5-min swimming session in the tank filled with water at $22-25^{\circ} \mathrm{C}$. Swimming behavior was videotaped and analyzed offline. The increased immobility time, which reflects the state of hopelessness/despair, was calculated (Mazarati et al, 2008, 2009, 2010).

\section{Plasma Corticosterone Assay and Combined Dexamethasone/Corticotropin Releasing Hormone Test}

Three to 6 days after FST (so that the latter would not interfere with the function of the HPA axis), $50 \mu \mathrm{l}$ of blood was collected from the tail vein into the EDTA-coated tubes and dexamethasone (DEX) $(0.03 \mathrm{mg} / \mathrm{kg}$; Sigma) was injected into the tail vein. Six hours later, blood was collected again, and animals were injected with corticotropin releasing hormone (CRH) (50 ng/kg, Sigma); the third blood sample was taken $30 \mathrm{~min}$ after the CRH injection. Corticosterone (CORT) was detected in plasma samples, using Immunochem Double Antibody Corticosterone 125I radioimmunoassay kit (MP Biomedicals, Orangeburg, NY). Dysregulation of the HPA axis consists of the elevated baseline CORT level, failure of DEX to suppress CORT, and the exacerbated increase of CORT in response to CRH (Johnson et al, 2006; Mazarati et al, 2009; Pohorecky et al, 2004; Zobel et al, 2004). 


\section{Autoradiographic Assays of 5-HT1A Receptors}

Three to six days after DEX/CRH test, animals were decapitated, brains were removed and stored at $-80^{\circ} \mathrm{C}$. Coronal $20 \mu \mathrm{m}$ thick sections were cut at the level of dorsal hippocampus (for the assay of postsynaptic receptors; Bregma -3.14 to $-3.6 \mathrm{~mm}$ ) and dorsal raphe (for the assay of presynaptic receptors; Bregma -7.64 to $-8.00 \mathrm{~mm}$; Paxinos and Watson, 1986).

The functional capacity of 5-HT1A receptors to activate G-protein was examined using $\left[{ }^{35} \mathrm{~S}\right] \mathrm{GTP} \gamma \mathrm{S}$ autoradiography (Hensler et al, 2007, 2010; Rossi et al, 2008). Sections were incubated with $40 \mathrm{pmol} / 1\left[{ }^{35} \mathrm{~S}\right] \mathrm{GTP} \gamma \mathrm{S}$, either in the absence or in the presence of the 5 -HT1A receptor agonist $( \pm)-8$ hydroxy-2-dipropylaminotetralin (8-OH-DPAT) at concentrations of $15 \mathrm{nmol}$ or $1 \mu \mathrm{mol}$, which produce $50 \%$ and maximal responses, respectively (Hensler and Durgam, 2001). Basal $\left[{ }^{35} S\right]$ GTP $\gamma S$ binding was determined in the absence of 8-OH-DPAT. Nonspecific $\left[{ }^{35} \mathrm{~S}\right] \mathrm{GTP} \gamma \mathrm{S}$ binding was defined in the absence of 8-OH-DPAT and in the presence of $10 \mu \mathrm{mol} / \mathrm{l} \mathrm{GTP} \gamma \mathrm{S}$. Sections were exposed to Kodak Biomax MR film (Amersham, Piscataway, New Jersey) for $48 \mathrm{~h}$.

Autoradiography of the binding of the 5-HT1A receptor antagonist $\left[{ }^{3} \mathrm{H}\right]$ WAY-100635 was performed to determine the number of 5-HT1A-binding sites (Hensler et al, 2007). Sections were incubated with $1.5 \mathrm{nmol} / 1\left[{ }^{3} \mathrm{H}\right] \mathrm{WAY}-100635$. This concentration of $\left[{ }^{3} \mathrm{H}\right] \mathrm{WAY}-100635$ is $10 \times$ the $\mathrm{Kd}$ value $(0.12 \mathrm{nmol}$; Gozlan et $a l, 1995)$ and is therefore saturating. Nonspecific binding was defined by incubating adjacent sections in the presence of $1 \mu \mathrm{mol} / \mathrm{l}$ NAN 190. Sections were exposed to Kodak BioMax MR Film (Amersham) for 9 weeks.

Digitized autoradiograms were analyzed using NIH Image software (ImageJ 1.42q). Autoradiograms of 8-OH-DPATstimulated $\left[{ }^{35} \mathrm{~S}\right] \mathrm{GTP} \gamma \mathrm{S}$ binding were quantified by the use of simultaneously exposed $\left[{ }^{14} \mathrm{C}\right]$ standards (ARC-146; American Radiochemicals). Nonspecific binding of $\left[{ }^{35} \mathrm{~S}\right] \mathrm{GTP} \gamma \mathrm{S}$ was subtracted from basal binding and from binding in the presence of $8-\mathrm{OH}-\mathrm{DPAT}$. Autoradiograms of $\left[{ }^{3} \mathrm{H}\right] \mathrm{WAY}-$ 100635 binding were quantified by the use of simultaneously exposed precalibrated $\left[{ }^{3} \mathrm{H}\right]$ standards (ART-123; American Radiochemicals, St Louis, Missouri). Optical density was converted to femtomoles/milligram of protein. Specific binding was calculated by subtracting nonspecific binding from total binding on adjacent sections.

\section{Fast Cyclic Voltammetry}

Fast cyclic voltammetry (FCV) allows measuring strength of the raphe-hippocampal serotonergic transmission in vivo (Bunin and Wightman, 1998; Jackson et al, 1995; Mazarati et al, 2008, 2010). Under urethane anesthesia $(1.25 \mathrm{~g} / \mathrm{kg})$, animals were implanted with a bipolar stimulating electrode into dorsal raphe (Bregma $-7.8 \mathrm{~mm}$; midline; ventral $6.5 \mathrm{~mm}$ ) and with a nafion-coated carbon fiber electrode (World Precision Instruments, Sarasota, FL) into the hippocampus (Bregma $-4.3 \mathrm{~mm}$; lateral $3 \mathrm{~mm}$; ventral 3.6). The release of serotonin in the hippocampus was induced by electrical stimulation of raphe (bipolar square wave pulses, $100 \mathrm{~Hz}, 200 \mathrm{~ms}, 0.35 \mathrm{~mA}$; Mazarati et al, 2008). The amount of released serotonin was measured by applying ramp current to the carbon fiber electrode (scanned from 0.2 to $1 \mathrm{~V},-0.1$ and $0.2 \mathrm{~V}$, at $1000 \mathrm{~V} / \mathrm{s}$; Mazarati et al, 2008, 2010). Oxidative peaks were acquired using POT500 scanning potentiostat (World Precision Instruments) before and after raphe stimulation. The difference between these two peaks (referred to as faradaic current) reflects the oxidation of serotonin released in response to the raphe stimulation (Wrona and Dryhurst, 1987).

\section{Mifepristone Administration}

Mifepristone is a blocker of glucocorticoid and progesterone receptors (Clark, 2008; Oitzl et al, 1998). However, in the dorsal raphe of male rats, mifepristone acts as a glucocorticoid receptor antagonist (Gregus et al, 2005; Klink et al, 2002; Martinez-Mota et al, 1999; Robichaud and Debonnel, 2005; Saavedra et al, 2006). A chronic system for the intraraphe delivery consisted of the ALZET osmotic pump 2001 (delivery rate $1.0 \mu \mathrm{l} / \mathrm{h}$, duration 7 days, volume $200 \mu \mathrm{l}$; Durect Corporation, Cupertino, CA) connected to the infusion cannula (28 gauge) via polypropylene catheter. Pumps were prefilled with either mifepristone (Cayman Chemical, Ann Arbor, MI; $50 \mathrm{nmol}$ dissolved in $10 \%$ dymethyl sulfoxide (DMSO)) or $10 \%$ DMSO (control). The implantation was done under isoflurane anesthesia using the coordinates described above for the FCV. A single cannula was placed into the dorsal raphe; two cannulae were implanted bilaterally into the hippocampi. Pumps were placed subcutaneously between the shoulders. Further assays were performed on days 5-7 of mifepristone delivery. At the end of drug infusion, pumps were removed, and the residual volume was aspirated; the latter did not exceed $20 \mu \mathrm{l}$.

In separate experiments, animals were implanted with guide 22-gauge cannula into raphe, and received a single bolus of mifepristone ( $350 \mathrm{nmol}$ ) 3-5 days later. FST was performed $30 \mathrm{~min}$ after the injection, and FCV immediately afterwards.

\section{Glucocorticoid Receptors Expression in Raphe Nucleus}

Rats were anesthetized with isoflurane, decapitated, brains were removed and frozen; raphe was dissected using holepunch biopsy and was homogenized in Trizol reagent. RNA concentration was measured using Quant-iT RNA Assay Kit (Invitrogen, Germany) and $100 \mathrm{ng}$ of total RNA was reverse transcribed with Quantitect Reverse Transcription Kit (Qiagen, Germany). Real-time polymerase chain reaction (PCR) was performed in Step One Real-time PCR system (Applied Biosystems) with QuantiTectTM SYBR Green PCR (Qiagen). Amplicons were amplified using glucocorticoid receptor specific primers $5^{\prime}$-TAC TTT GCC TTC CAC TGG TT 3', 1283-1303 bp and 5'-CTA ACT CAC GGC CAC AGT GGG TT 3', 1550-1568 bp, GenBank accession number AY029071 (Sah et al, 2005). Relative mRNA quantity was expressed as a ratio of glucocorticoid receptor mRNA to the expression of the house keeping gene GAPDH.

\section{Intrahippocampal Administration of 8-OH-DPAT}

8-OH-DPAT (Sigma) was injected bilaterally into the hippocampus (Bregma $-4.3 \mathrm{~mm}$; lateral $3 \mathrm{~mm}$; ventral 3.6; 
1 and $10 \mathrm{nmol}$ ) following the procedure described for acute mifepristone injection. FST was performed $30 \mathrm{~min}$ after 8-OH-DPAT administration.

\section{Data Analysis}

Data were analyzed using Prism 4 software (GraphPad, San Diego, CA). Statistical tests and sample sizes are described in respective Results sections and/or figure legends.

\section{RESULTS}

\section{Seizures, Behavioral and Endocrine Impairments in Post-SE Rats}

All post-SE rats exhibited spontaneous behavioral stage 4-5 seizures, during the 2 weeks of monitoring. Across all groups described below (total $n=131$ ), minimal/maximal/ median seizure count over the 2 weeks was 1/35/10.5.

During the 5-min swimming session, control animals $(n=13)$ mainly exhibited escaping and/or exploring behavior, while the cumulative immobility time accounted on average for $1 \mathrm{~min}$. In post-SE rats $(n=22)$, cumulative immobility time was twice as long, as compared with controls (Figure 1a). There was significant interaction between the group assignment (ie naive and post-SE), the outcomes of CORT radioimmunoassay $(\mathrm{F}=61.85$, $p<0.001)$. Baseline plasma CORT levels were significantly higher in post-SE than in naive subjects. Furthermore in contrast to naive rats, in post-SE animals DEX was ineffective in suppressing plasma CORT levels, while CRH induced an exacerbated increase in plasma CORT (Figure 1b). The observed behavioral and endocrine impairments confirmed previously shown depressive behavior and the dysregulation of the HPA axis following SE (Mazarati et al, 2008, 2009). Neither the immobility time in the FST nor plasma CORT levels statistically correlated with the frequency of spontaneous seizures (Spearman $r=-0.02$ for immobility time and -0.28 for CORT after CRH injection, $p>0.05)$.

Based on the severity of behavioral impairments in the FST, we divided post-SE rats into two groups: those animals in which cumulative immobility time was $\leqslant 100 \mathrm{~s}$ (ie accounted for $1 / 3$ or less of the total swimming time, $n=11$ ) were classified as moderately depressed, and those in whom cumulative immobility time was $>100$ s (ie more than $1 / 3$ of total swimming time, $n=11$ ), as animals with severe depression (Figure 1c). In agreement with our earlier findings (Mazarati et al, 2009), the severity of depressive behavioral impairment in post-SE animals positively correlated with the extent of the dysregulation of the HPA axis, while no correlation was observed between the behavioral and endocrine measurements in naive rats (Figure 1c).

Further analysis of subgroups of post-SE animals showed that even in moderately impaired rats, performance in the FST was significantly worse, and the extent of the hyperactivity of the HPA axis (measured as plasma CORT level in response to CRH) was significantly higher than in naive subjects (Figures $1 \mathrm{c}$ and $2 \mathrm{a}$ and $\mathrm{b}$ ). At the same time, both behavioral and endocrine abnormalities were statistically more significant in animals with severe a
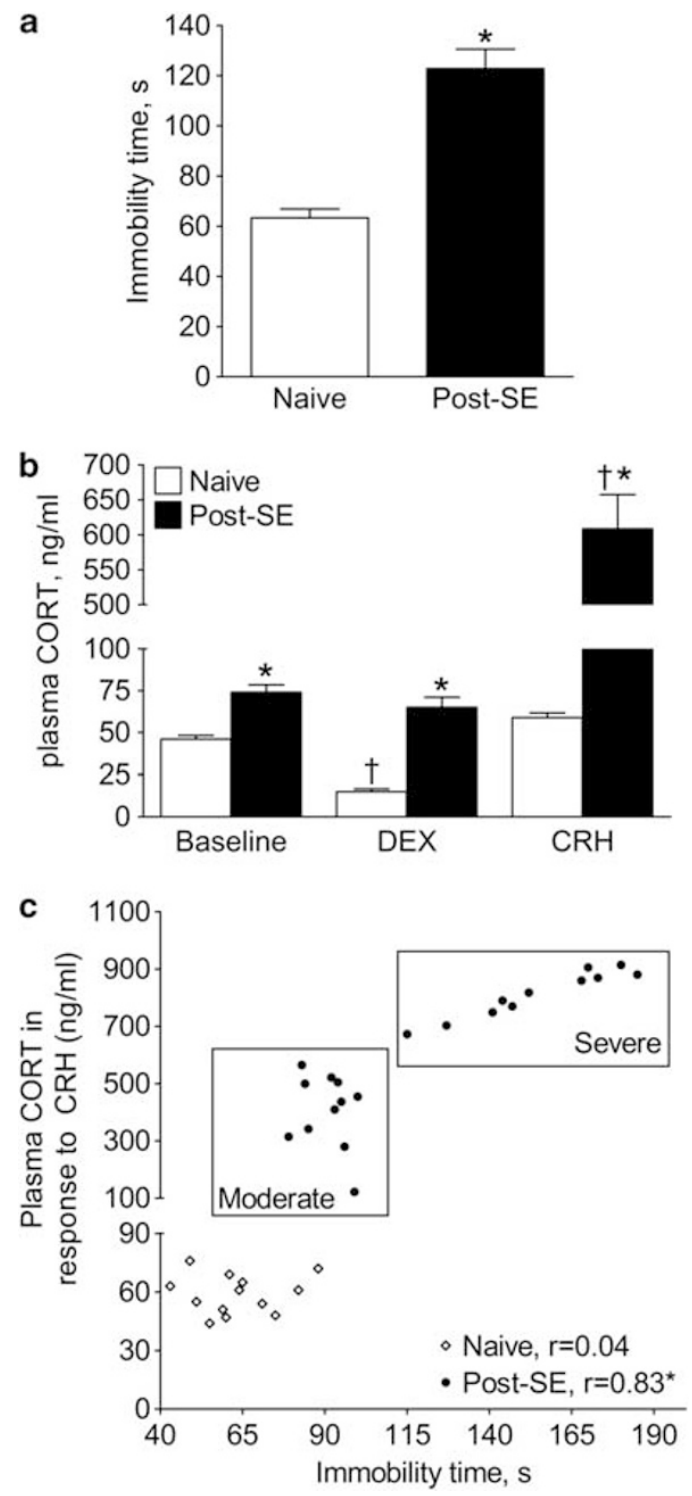

Figure I Behavioral and endocrine impairments in post-SE animals. (a) Immobility time in the FST was significantly longer in post-SE rats $(n=22)$, than in naive subjects $(n=13)$. Data are presented as mean \pm SEM; ${ }^{*} p<0.05$, post-SE vs naive (Mann-Whitney test). (b) In post-SE rats, baseline plasma CORT levels were significantly higher than in controls. In naive rats, DEX significantly suppressed plasma CORT levels; the latter returned to the pre-DEX value after $\mathrm{CRH}$ injection. In post-SE animals, DEX failed to suppress plasma CORT; CRH led to the exacerbated increase of CORT as compared with controls. Data are presented as mean \pm SEM; ${ }^{*} p<0.05$, post-SE vs naive; ${ }^{\dagger} p<0.05$, effects of either DEX or $\mathrm{CRH}$ vs respective baseline (two-way repeated measures ANOVA + Bonferroni post hoc test). (c) Immobility time in the FST is plotted against plasma CORT level in response to CRH injection. Breakdown of post-SE animals into subsets of moderately and severely depressed based on their performance in the FST is indicated by the outlining squares. In post-SE rats, statistically significant positive correlation was detected between the duration of the immobility time in the FST and plasma CORT concentration in response to $\mathrm{CRH}$. No correlation between the two parameters was observed in control subjects. Spearman correlation coefficients are indicated next to the group symbols; $*_{p}<0.05$, post-SE vs naive. No statistical correlation was observed between the immobility time in the FST and any other CORT measurements (baseline and response to DEX) in both control and post-SE rats (data not shown). 

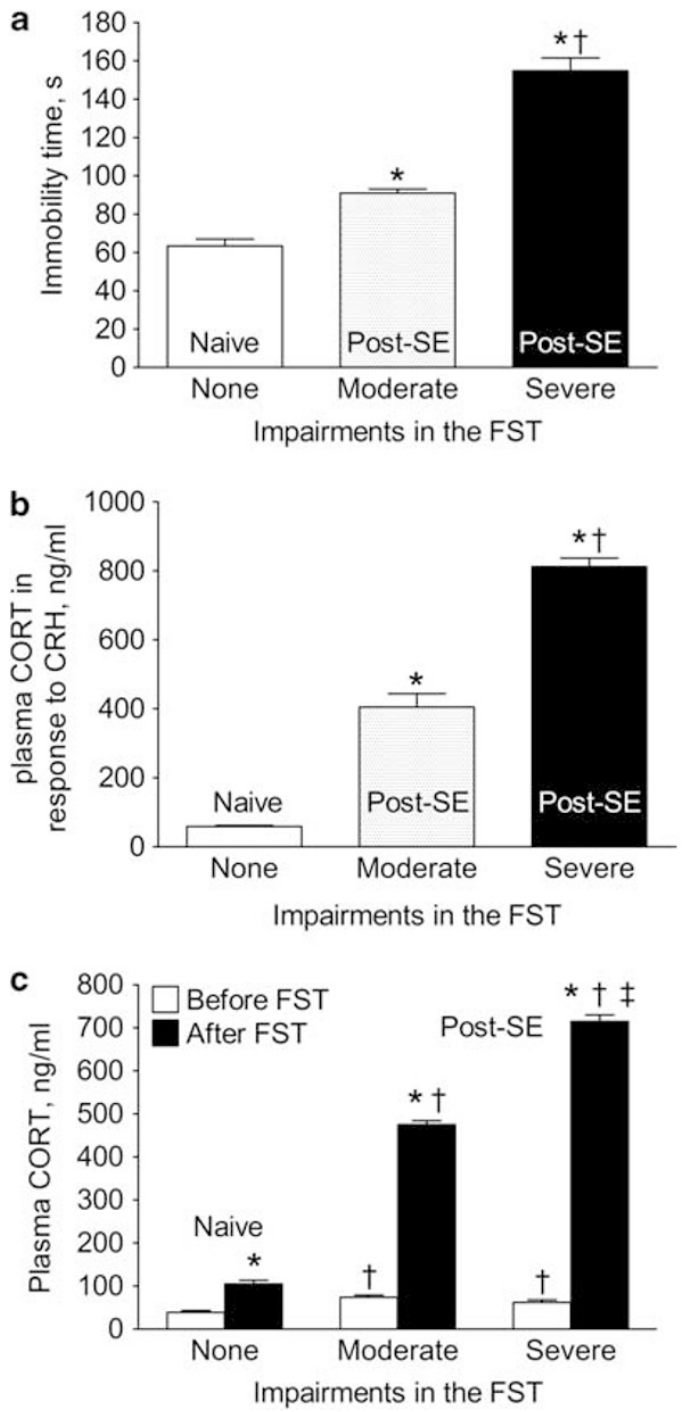

Figure 2 Behavioral and endocrine impairments in moderately and severely depressed post-SE rats. (a) Based on their performance in the FST, post-SE rats were divided into two subsets-moderately and severely depressed. Data are presented as mean \pm SEM. $* p<0.05$ for post-SE vs naive; ${ }^{\dagger} p<0.05$ for post-SE severe vs post-SE moderate (Kruskall-Wallis test followed by post hoc Mann-Whitney tests). (b) The rise of plasma CORT in response to $\mathrm{CRH}$ was significantly steeper in animals with severe, than in those with moderate depressive impairments. * $p<0.05$ for post-SE vs naive; ${ }^{\dagger} p<0.05$ for post-SE severe vs post-SE moderate (one-way ANOVA followed by post hoc Neuman-Keuls test. (c) Plasma CORT level in naive, moderately, and severely impaired post-SE rats 15 min after the completion of 5 -min swimming session. * $p<0.04$, after FST vs before FST; ${ }^{\dagger} p<0.05$, moderate and severe vs none. ${ }^{\ddagger} p<0.05$, severe vs moderate.

impairments than in moderately impaired post-SE rats (Figure $2 \mathrm{a}$ and $\mathrm{b}$ ).

We suggested that the increase of plasma CORT level in response to $\mathrm{CRH}$ was mimicking the reaction of the HPA axis to stressful stimuli in both naive and post-SE subjects. In order to confirm this assertion experimentally, we measured plasma CORT levels after the 5-min forced swimming session. There was significant interaction between the group assignment (ie naive, moderate and severe impairments) and the measurements of plasma CORT concentration $(\mathrm{F}=54.31, p<0.001)$. Fifteen minutes after

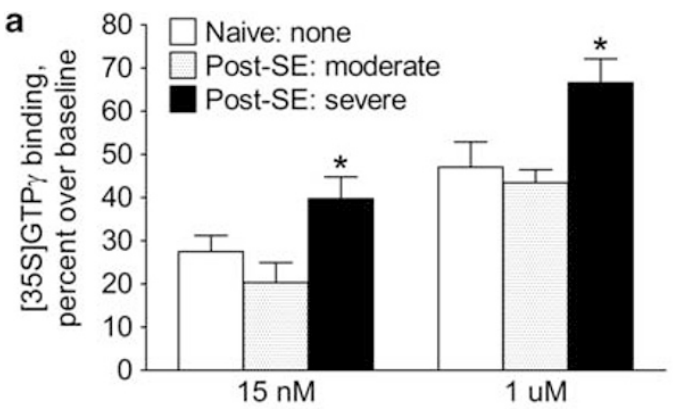

Concentration of 8-OH-DPAT

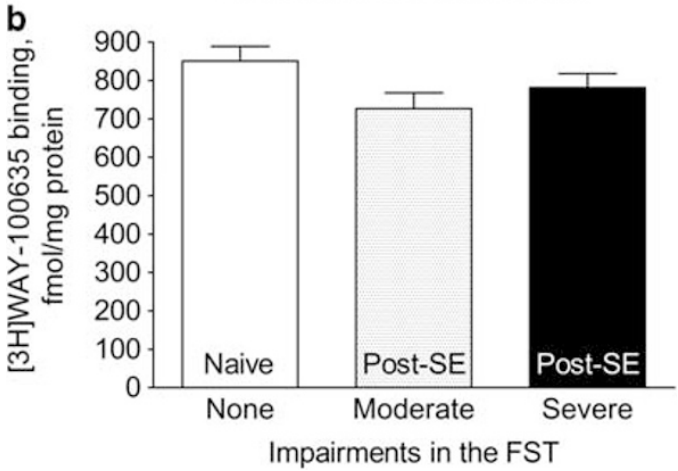

Figure 3 8-OH-DPAT-stimulated $\left[{ }^{35} \mathrm{~S}\right] \mathrm{GTP} \gamma \mathrm{S}$ binding and $\left[{ }^{3} \mathrm{H}\right]$ WAY100635 binding in dorsal raphe of naive and post-SE rats. (a) ${ }^{35}$ S] GTP $\gamma S$ binding stimulated by the 5-HTIA receptor agonist 8-OH-DPAT at each concentration (ie $15 \mathrm{nM}$ or $1 \mu \mathrm{M}$ ) is shown as mean \pm SEM for naive and the two subsets of post-SE rats. * $p<0.05$ post-SE severe vs both naive and post-SE moderate (two-way ANOVA + Bonferroni post hoc test). (b) The specific binding of the 5-HTIA receptor antagonist $\left[{ }^{3} \mathrm{H}\right]$ WAY-I00635 in dorsal raphe was statistically similar in naive and post-SE rats (one-way ANOVA + Neuman-Keuls post hoc test). Data are presented as mean \pm SEM.

the completion of the FST, levels of plasma CORT were increased in both naive and post-SE rats. The extents of these increases were comparable to the ones observed in response to $\mathrm{CRH}$ injections during DEX/CRH test: $\sim 2.5$ fold in naive animals $(n=6)$; 7 -fold in rats with moderate behavioral impairments $(n=6)$, and 14 -fold in severely depressed subjects ( $n=7$; Figure $2 \mathrm{c}$ ).

\section{Characterization of Presynaptic (Raphe) 5-HT1A Receptors}

There was no interaction between the group assignment (ie naive, moderate and severe impairments) and $\left[{ }^{35} \mathrm{~S}\right] \mathrm{GTP} \gamma \mathrm{S}$ binding $(\mathrm{F}=0.3, p>0.05) .\left[{ }^{35} \mathrm{~S}\right] \mathrm{GTP} \gamma \mathrm{S}$ binding stimulated by the 5 -HT1A receptor agonist $8-\mathrm{OH}-\mathrm{DPAT}$ ( $15 \mathrm{nM}$ or $1 \mu \mathrm{M})$ in dorsal raphe was statistically similar between naive and all post-SE rats (ie those with moderate and severe depressive impairments combined, not shown). Further, no significant differences were observed between naive and moderately impaired rats (Figure 3a). However, in raphe of severely depressed animals, $\left[{ }^{35} \mathrm{~S}\right] \mathrm{GTP} \gamma \mathrm{S}$ binding stimulated by both low and high concentrations of 8-OH-DPAT was statistically higher than both in naive rats and in animals with moderate impairments in the FST $(\mathrm{F}=10.2, p<0.001$; Figure 3a). 
$\left[{ }^{3} \mathrm{H}\right]$ WAY-100635 binding in dorsal raphe was statistically similar between naive and all post-SE rats (ie animals with moderate and severe behavioral impairments combined; not shown). Furthermore, no alterations in the number raphe 5-HT1A-binding sites was observed in severely impaired animals as compared with both naive and moderately impaired rats (Figure 3b).

The obtained results suggested selective enhancement of presynaptic 5-HT1A receptor function, but not of their number, in animals that exhibited severe depressive behavior and excessively hyperactive HPA axis.

Neither $\left[{ }^{35} \mathrm{~S}\right] \mathrm{GTP} \gamma \mathrm{S}$ nor $\left[{ }^{3} \mathrm{H}\right]$ WAY-100635 binding in the dorsal raphe statistically correlated with the frequency of spontaneous seizures (Spearman $r=-0.24$ at $15 \mathrm{nM} 8-\mathrm{OH}-$ DPAT and 0.28 at $1 \mu \mathrm{M}$ 8-OH-DPAT-stimulated $\left[{ }^{35} \mathrm{~S}\right] \mathrm{GTP} \gamma \mathrm{S}$ binding; $r=0.42$ for $\left[{ }^{3} \mathrm{H}\right]$ WAY-100635 binding, all $p>0.05$ ).

\section{Effects of Intraraphe Mifepristone Administration}

We suggested that the enhanced function of presynaptic 5-HT1A receptors in severely depressed animals was driven by the excessively hyperactive HPA axis on the one hand, and that this enhancement of 5-HT1A function underlay the detected behavioral depressive impairments on the other hand. In order to confirm this suggestion experimentally, we examined whether the dissociation of circulating glucocorticoids from raphe glucocorticoid receptors would alleviate epilepsy-associated depressive behavior. There was significant interaction between the group assignment (ie naive, moderately and severely depressed) and the outcome of mifepristone treatment measured in the FST $(\mathrm{F}=16.67$, $p<0.001)$. One-week long delivery of mifepristone into dorsal raphe did not modify behavior in both naive $(n=8$, mifepristone; $n=9$, DMSO) and moderately impaired ( $n=6$, mifepristone; $n=6$, DMSO) animals. At the same time, mifepristone administration significantly alleviated (although did not completely reverse) behavioral deficits in severely depressed rats $(n=9$, mifepristone; $n=9$, DMSO; Figure 4a).

We further examined whether the diminished serotonin output in the raphe-hippocampal pathway (which presumably was a result of raphe 5-HT1A activation and a cause of depressive behavioral impairments) could be improved by pharmacological blockade of raphe glucocorticoid receptors. In agreement with our earlier findings (Mazarati et al, 2008,2010 ), the amplitude of serotonin oxidative peaks in the hippocampus in response to raphe stimulation was lower in post-SE animals than in controls, thus pointing towards the diminished raphe-hippocampal serotonergic transmission under conditions of chronic epilepsy. Furthermore, the deficit of raphe-hippocampal serotonergic transmission was more profound in animals with severe depression, than in moderately impaired subjects (Figure $4 \mathrm{~b}$ and c).

There was significant interaction between the group assignment (ie naive, moderately and severely depressed post-SE rats; sample sizes are same as for Figure 4a) and the effects of mifepristone on the measurements in the FCV assay $(\mathrm{F}=11.86, p<0.001)$. In naive animals as well as in moderately depressed animals, 1-week long intraraphe infusion of mifepristone had no effect on hippocampal serotonin release in response to raphe stimulation. At the
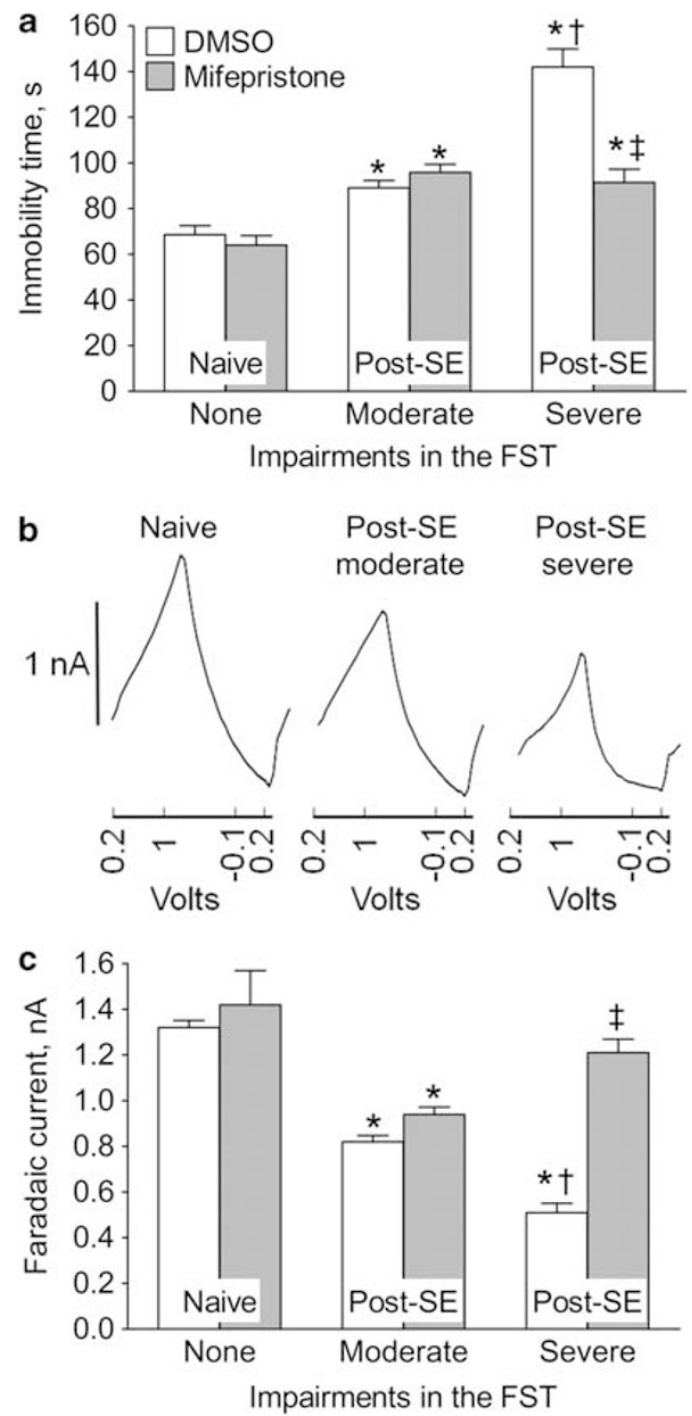

Figure 4 Effects of mifepristone administration into raphe nucleus on behavior in the FST and serotonin release in the raphe-hippocampal pathway. (a) Effects of mifepristone on the performance in the FST in naive and the two subsets of mifepristone and DMSO-treated rats are presented as mean \pm SEM. (b) Example of voltagrams obtained from the hippocampus in response to raphe stimulation in naive, moderately depressed, and severely depressed post-SE rats. Each tracing represents an average of five consecutive scans $0.1 \mathrm{~s}$ apart. Note progressive decline in the amplitude of faradaic currents. (c) Effects of mifepristone on the amplitude of faradaic currents in naive and the two subsets of mifepristone and DMSO-treated rats is presented as mean \pm SEM. $(a, b) * p<0.05$, post$\mathrm{SE}$ vs naive; ${ }^{\dagger} p<0.05$ post-SE severe, vs post-SE moderate; ${ }^{\ddagger} p<0.05$ Mifepristone vs DMSO (two-way ANOVA followed by Bonferroni post hoc test).

same time, in severely depressed rats, treatment with mifepristone restored the examined parameter to the level observed in naive subjects (Figure 4c).

Intraraphe infusion of mifepristone for 1 week did not affect functional state of the HPA axis in both control and post-SE rats, neither it modified frequency of spontaneous seizures in post-SE animals (not shown).

Single acute injection of mifepristone $(350 \mathrm{nmol})$ into the raphe of post-SE animals improved neither behavioral nor biochemical impairments examined by the FST and FCV, 
respectively ( $n=6$ per group: naive, moderately, and severely impaired post-SE rats treated with either DMSO or mifepristone; data not shown).

\section{Glucocorticoid Receptor Expression in Raphe Nucleus}

In order to address the possibility that the selective antidepressant effects of mifepristone in post-SE rats could be due to the epilepsy-related increase of the expression of raphe glucocorticoid receptors, rather than due to the hyperactivity of the HPA axis alone, we compared the expression of glucocorticoid receptors in raphe nucleus of post-SE animals with severe depressive impairments $(n=7)$ and naive $(n=7)$ rats. Relative mRNA content, normalized against GAPDH was $3.35 \pm 1.61$ in naive, and $3.65 \pm 1.65$ in post-SE animals ( $p>0.05$, Mann-Whitney test).

\section{Characterization of Postsynaptic (Hippocampal) 5-HT1A Receptors}

There was no interaction between the group assignment (ie naive, moderate and severe impairments) and $\left[{ }^{35} \mathrm{~S}\right] \mathrm{GTP} \gamma \mathrm{S}$ binding $(\mathrm{F}=1.55, p>0.05)$. At $15 \mathrm{nM}$ of 8 -OH-DPAT, $\left[{ }^{35} \mathrm{~S}\right] \mathrm{GTP} \gamma \mathrm{S}$ binding was similar among the groups of naive $(n=13)$, moderately depressed $(n=11)$, and severely depressed $(n=11)$ post-SE rats across all examined areas (ie CA1, CA3, and dentate gyrus; Figure 5a). At the same time, $\left[{ }^{35} \mathrm{~S}\right] \mathrm{GTP} \gamma \mathrm{S}$ binding in response to $1 \mu \mathrm{M}$ of $8-\mathrm{OH}-$ DPAT was statistically lower in CA1 and CA3 of post-SE
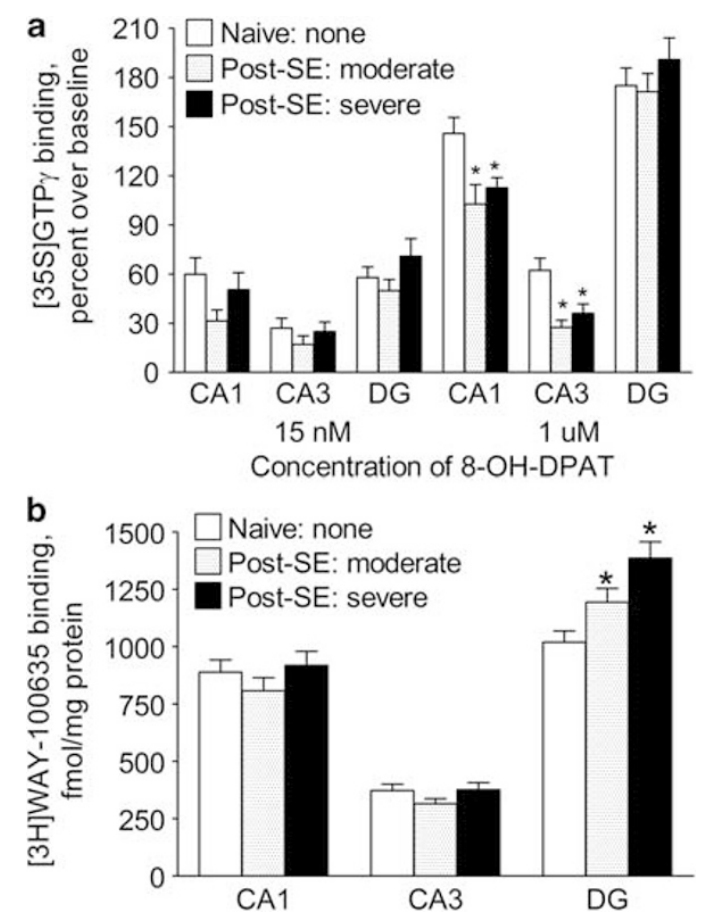

Figure 5 8-OH-DPAT-stimulated $\left[{ }^{35} \mathrm{~S}\right] \mathrm{GTP} \gamma \mathrm{S}$ binding and $\left[{ }^{3} \mathrm{H}\right] \mathrm{WAY}$ 100635 binding in the hippocampus of naive and post-SE rats. (a) In CAI and CA3 areas of the hippocampus of all post-SE animals, $\left.{ }^{35} \mathrm{~S}\right] \mathrm{GTP} \gamma \mathrm{S}$ binding was significantly lower in response to $1 \mu \mathrm{M}$ 8-OH-DPAT, than in controls. (b) In dentate gyrus (DG) of all post-SE animals, the specific binding of $\left[{ }^{3} \mathrm{H}\right]$ WAY- 00635 was significantly higher than in controls. $(a, b)$ Data are presented as mean $\pm \mathrm{SEM}$; ${ }^{*} p<0.05$, post-SE vs naive (two-way ANOVA + Bonferroni post hoc test). animals than in respective areas of control rats $(F=9.39$, $p<0.001$ ), thus suggesting the diminished function of postsynaptic 5-HT1A receptors. The extent of attenuation of 5-HT1A receptor function was similar between moderately and severely impaired rats (Figure 5a).

There was significant interaction between the group assignment (ie naive, moderate and severe impairments) and $\left[{ }^{3} \mathrm{H}\right] \mathrm{WAY}-100635$ binding $(\mathrm{F}=4.31, p<0.05)$. No statistical differences were detected between naive and post-SE animals (both subgroups) in the number of 5-HT1A receptor binding sites in CA1 and CA3; in dentate gyrus of all post-SE subjects, the number of binding sites was significantly higher than in controls (Figure 5b).

In naive and post-SE rats, both the function and the number hippocampal 5-HT1A receptors was statistically independent of spontaneous seizure frequency (not shown).

\section{Effects of Intrahippocampal Mifepristone Administration}

Because there were no differences between the subsets of moderately and severely depressed animals in terms of both $\left[{ }^{35} \mathrm{~S}\right] \mathrm{GTP} \gamma \mathrm{S}$ and $\left[{ }^{3} \mathrm{H}\right] \mathrm{WAY}-100635$, effects of intrahippocampal mifepristone on behavior were only examined in a subset of rats with severe behavioral abnormalities. There was no interaction between the group assignment (ie naive and post-SE) and effects of treatment $(\mathrm{F}=1.16, p>0.05)$. Intrahippocampal infusion of mifepristone did not modify behavior in the FST in both naive $(n=9)$ and post-SE
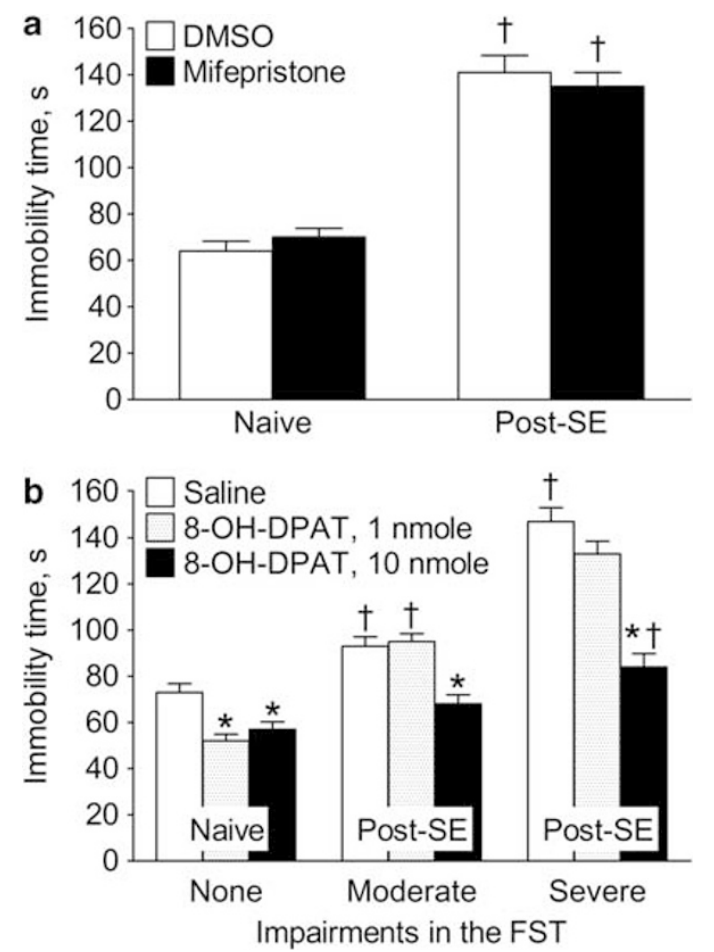

Figure 6 Effects of intrahippocampal administration of mifepristone and 8-OH-DPAT on behavior in the FST. (a) Effects of intrahippocampal mifepristone administration. Data are presented as mean \pm SEM. ${ }^{\dagger} p<0.05$ post-SE vs naive (two-way ANOVA + Bonferroni post hoc test). (b) Effects of intrahippocampal 8-OH-DPAT administration. Data are presented as mean \pm SEM. ${ }^{*} p<0.05,8-O H-D P A T$ vs saline; ${ }^{\dagger} p<0.05$, post-SE vs naive (two-way ANOVA + Bonferroni post hoc test). 
subjects $(n=9)$ as compared with DMSO-treated rats $(n=9$ per group, Figure 6a). Frequency of spontaneous seizures was not modified by intrahippocampal mifepristone administration (not shown).

\section{Effects of Intrahippocampal 8-OH-DPAT Administration}

We examined whether the observed downregulation of hippocampal 5-HT1A receptors could have been a contributing factor in epilepsy-associated depressive impairments. To answer this question, both naive and post-SE rats were injected into the hippocampus with two doses of 5-HT1A agonist 8-OH-DPAT. There was significant interaction between the group assignment (ie naive, moderately and severely depressed post-SE rats) and performance in the FST $(\mathrm{F}=12.5, p<0.01)$. At both 1 and $10 \mathrm{nmol}(n=6$ per group per treatment), 8-OH-DPAT significantly shortened immobility time in the FST in naive subjects, without statistical differences between the two doses (Figure 6b). In both subsets of post-SE rats, 8-OH-DPAT treatment was ineffective at $1 \mathrm{nmol}$; however, it significantly improved performance in the FST at $10 \mathrm{nmol}$, to the equal extent in moderately and severely depressed animals (Figure 6b).

\section{Limitations of the Study}

Due to technical reasons, the examination of effects of intraraphe and intrahippocampal mifepristone administration on the function and number of raphe and hippocampal 5-HT1A receptors could not be performed. Pilot experiments in nine animals showed that the described studies were not feasible because in vivo experimental procedures (such as electrode implantation and continuous drug infusion) rendered tissue inamenable to further autoradiographic assays.

\section{DISCUSSION}

Earlier experiments implicated both the deficiency of central serotonergic transmission and the dysregulation of the HPA axis in the evolvement of depression-like behavioral abnormalities in animals with chronic epilepsy (Mazarati et al, 2008, 2009). The present study suggests that under certain conditions, the hyperactive HPA axis may positively regulate presynaptic 5 -HT1A receptors (ie those in raphe nucleus); that the resulting enhanced function of presynaptic 5-HT1A receptors may be a factor limiting the release of serotonin from raphe neurons into the terminals; and that the deficiency of raphe-hippocampal serotonergic transmission may be ultimately contributing into (albeit not solely defining) behavioral depressive impairments. In addition, depression may be further exacerbated by the downregulation of postsynaptic 5-HT1A receptors (ie those in the hippocampus; the increase in the number of postsynaptic 5-HT1A-binding sites in dentate gyrus is discussed later on).

Several studies have shown the upregulation of presynaptic 5-HT1A receptors in patients with major depression (Lemonde et al, 2003; Parsey et al, 2006); such activation would shift serotonin release in favor of the short-feedback autoinhibitory loop and thus represents a conceivable cause of the paucity of ascending serotonergic projections, as well as a target for therapeutic interventions using selective serotonin reuptake inhibitors (SSRIs; Chaput et al, 1986; Le Poul et al, 1995; Maudhuit et al, 1997). Along the same lines, in TLE patients suffering from comorbid depression, positive correlation was reported between the severity of clinical symptoms of depression and the binding capacity of raphe 5-HT1A receptors (Lothe et al, 2008). In our experiments, the functional capacity of presynaptic 5HT1A receptors significantly varied among epileptic animals, and so did the severity of depressive impairments. The segregation of post-SE rats into two subsets based on their performance in the FST revealed that in severely depressed subjects, the function of raphe 5-HT1A receptors was indeed significantly enhanced, while in animals with moderate impairments, the function of raphe 5-HT1A receptors remained within normal levels. Therefore, the presumable suppression of serotonin release by presynaptic 5-HT1A receptors appears to have role in more severe depressive aberrations, while moderate impairments may stem from other causes. Indeed, besides the short-feedback autoinhibitory loop, afferent serotonin projections are controlled by a multitude of other extrinsic and intrinsic mechanisms (eg long-loop negative-feedback system activated by postsynaptic 5-HT1A receptors; excitatory noradrenergic projection from locus coeruleus; neuropeptide galanin acting via galanin type 1 and type 2 receptors; Ceci et al, 1994; Hajos et al, 1999; Hokfelt et al, 1998; Lu et al, 2005; Mazarati et al, 2005), all of which may be involved in epilepsy-associated depression. However, within the framework of our studies, it should be noticed that changes in presynaptic 5-HT1A receptors were specifically limited to alterations in their function, but not the number, as it was evident from $\left[{ }^{3} \mathrm{H}\right]$ WAY-100635 autoradiography.

Along with the differences in the function of presynaptic 5-HT1A receptors, the two subsets of post-SE animals were characterized by different extent of the dysregulation of the HPA axis: while the hyperactivity of the HPA axis was observed in all post-SE rats, the increase of plasma CORT in response to CRH was far steeper in rats with severe depressive impairments than in those with moderate behavioral abnormalities. This observation confirms our earlier finding of positive correlation between the severity of depressive behavior and the hyperactivity of the HPA axis following SE (Mazarati et al, 2009). The hyperactivity of the HPA axis may lead to depression via several mechanisms, including both direct and glutamate-mediated neurotoxicity in the hippocampus, both mechanisms being highly relevant in TLE (for review see Kondziella et al (2007)). However, in an attempt to connect the observed neuroendocrine, biochemical, and behavioral abnormalities in postSE animals, we focused our attention on the interaction between the HPA axis and presynaptic 5-HT1A receptors. Experimental evidence suggests both positive and negative regulation of 5-HT1A autoreceptors by circulating glucocorticoids (Bellido et al, 2004; De Kloet et al, 1986; Judge et al, 2004; Man et al, 2002); as it has been pointed in the Introduction, the reported controversial findings may reflect complex state-dependent regulation of serotonergic mechanisms by the HPA axis (Judge et al, 2004). Because the upregulation of raphe 5-HT1A receptors was observed in post-SE rats with only excessively strong response to 
$\mathrm{CRH}$, we suggested that under normal (as in naive rats) or close to normal (as in moderately impaired rats) functioning of the HPA axis, the latter has no role in regulating 5HT1A autoreceptors. In contrast, when the HPA axis is excessively dysregulated (as it was in severely impaired animals), it becomes the pivotal factor in positively driving the function of raphe 5-HT1A receptors.

The HPA hyperactivity was mimicked in our studies by $\mathrm{CRH}$ injection, but may also occur under conditions of severe stress. For example, prolonged $(15 \mathrm{~min})$ forced swimming in rats results in the increase of plasma CORT level comparable to the level observed by us after CRH injection to post-SE animals (Connor et al, 2000; Finn et al, 2003). Furthermore, in our studies, $5 \mathrm{~min}$ long swimming session itself induced the increase of plasma CORT levels in naive and in both subsets of post-SE rats comparable to those observed upon $\mathrm{CRH}$ injections in all three groups (ie progressive response across naive-moderately impairedseverely impaired animals).

Selective positive regulation of presynaptic 5-HT1A receptors by excessively dysregulated HPA axis would suggest that the blockade of the access of circulating glucocorticoids to raphe nucleus would (a) attenuate the function of raphe 5-HT1A receptors, (b) reverse the deficiency of raphe-hippocampal serotonergic transmission, and (c) improve behavioral depressive deficits in severely depressed, but not in naive and moderately impaired animals. Based on these assumptions, we examined effects of intraraphe infusion of mifepristone on epilepsy-associated depression.

In agreement with our contention, protracted pharmacological blockade of raphe glucocorticoid receptors significantly improved behavioral impairment in severely depressed post-SE rats, but had no effect in naive and moderately depressed animals. It should be noticed that the lack of effects of acutely injected mifepristone suggests that the observed behavioral alterations stemmed from prolonged chronic exposure of raphe nucleus to the excessively dysregulated HPA axis. However, the effect of mifepristone on serotonin release from the hippocampus was not as straightforward. In line with the presumed role of raphehippocampal serotonergic deficiency in the development of depressive impairments in the FST, we observed progressive decline of serotonin release in response to raphe stimulation in moderately and severely depressed rats. Lack of effects of mifepristone on raphe-hippocampal serotonergic transmission in naive and moderately impaired rats also supported our suggestion that glucocorticoids have no major role in regulating afferent serotonergic projections under normal and close to normal function of the HPA axis. At the same time, the action of mifepristone in animals with severe depressive impairments was surprising: one would expect that the treatment would partially improve serotonergic deficit by bringing it to the level detected in moderately impaired rats. Instead, in these animals we observed complete reversal of raphe-hippocampal serotonergic deficiency, so that electrochemical correlates of serotonin release were statistically similar between naive animals and mifepristone-treated severely depressed rats. On the one hand, the obtained result may merely reflect imperfection of the applied technique (ie FCV in vivo), and therefore more advanced methodology might be able to reveal more subtle changes in the examined parameter. On the other hand, assuming that the assay was sufficiently accurate, the obtained data may suggest that moderate and severe depressive impairments following SE do not represent a continuum, that is do not stem from progressive deterioration of the same mechanism(s) and pathway(s); rather, the two observed patterns of behavioral abnormalities may have two entirely different pathophysiological backgrounds: while severe impairments result from the HPA axis-5HT1A receptor interaction, moderate aberrations may involve distinct mechanisms, which are yet to be identified. While acknowledging the limitations of animal models for studying any neuropsychiatric phenomena, the latter assumption may have important clinical implications in dictating the need of different treatment strategies not just for different symptoms of depression (eg despair $v s$ anhedonia $v s$ social self-isolation), but also for different gradations of the same symptom (eg state of despair $v s$ explicit suicidal ideation).

Because of the aforementioned technical limitations, we were unable to confirm directly that treatment with mifepristone attenuated the function of raphe 5-HT1A receptors in post-SE rats. However, recent experimental study showed that prolonged treatment with an SSRI fluoxetine suppresses the expression of raphe glucocorticoid receptors with the time course congruent with the onset of the drug's antidepressant effect (Heydendael and Jacobson, 2010). The implication that the attenuation of effects of circulating glucocorticoids on dorsal raphe may be one of the mechanisms underlying antidepressant action of fluoxetine (although this does not exclude the established mechanism involving the desensitization of presynaptic 5HT1A receptors by the increased concentration of serotonin in the synaptic cleft) is in line with our finding that direct antagonism of raphe glucocorticoid receptors alleviated both behavioral and biochemical symptoms of depression.

Another important result of mifepristone experiment was the observed dissociation between the effects of the drug on serotonin release and behavior in animals with severe depressive impairments. The fact that complete restoration of the serotonin release in the hippocampus was accompanied only by partial improvement of behavioral deficit in the FST suggested that even within the subset of severely impaired rats raphe-hippocampal serotonin deficit was not the sole mechanism underlying depression. Since major depression is a multifactorial disorder, it is also highly likely that epilepsy-associated depression also has multiple contributing mechanism (among others, imbalance in glutamatergic, GABAergic, noradrenergic, and dopaminergic systems has been discussed; Kondziella et al, 2007). From this standpoint, the observed desensitization of postsynaptic 5-HT1A receptors in CA1 and CA3 may contribute to the evolvement of depression in post-SE rats independently of the deterioration of presynaptic component of central serotonergic transmission. It should be noticed that while the reduction of postsynaptic 5-HT1A receptor function was only observed at $1 \mu \mathrm{M}$ of $8-\mathrm{OH}-$ DPAT, this effect was unlikely due to a nonspecific effect of the drug (ie not related to 5 -HT1A receptors): $1 \mu \mathrm{M}$ represents an $E_{\max }$ concentration based on curves generated using eight incremental concentrations of 8-OH-DPAT $(1 \mathrm{nM}-10 \mu \mathrm{M}) . \quad\left[{ }^{35} \mathrm{~S}\right] \mathrm{GTP} \gamma \mathrm{S}$ binding stimulated by this 
concentration of 8-OH-DPAT in hippocampus was completely blocked by the selective 5-HT1A receptor antagonist WAY-100635 (100 nM; Hensler and Durgam, 2001), and was not altered by the selective 5-HT7 receptor antagonist SB 269970 (100 nM; Rossi et al, 2006).

Reduced binding of hippocampal 5-HT1A receptors has been reported in patients with major depression (Sargent et al, 2000), as well as in those TLE patients who suffer from concurrent depression (Giovacchini et al, 2005). Along these lines, the observed antidepressant effect of intrahippocampally injected 5-HT1A agonist confirms the importance of postsynaptic 5-HT1A receptors in mediating depressive behavior, as well as adaptive behavior in the FST in general, as the drug effectively reduced the immobility time in naive rats. Furthermore, the rightward shift in the effects of 8-OH-DPAT in post-SE animals, as compared with naive rats may serve as an indirect confirmation of the declined function of these receptors in post-SE rats.

The increased number of 5-HT1A-binding sites in the dentate gyrus does not fit serotonergic hypothesis of depression in post-SE animals. Serotonin acting via 5HT1A receptors is known to promote neuronal progenitor proliferation in dentate gyrus (Gould, 1999). Furthermore, the suppression of dentate gyrus neurogenesis, particularly by high concentrations of glucocorticoids, has been implicated in mechanisms of depression (Djavadian, 2004; Gould and Tanapat, 1999). At the same time, post-SE chronic epilepsy is characterized by the increased neuronal progenitor proliferation in dentate gyrus (Parent et al, 1997), although functional significance of this phenomenon remains debatable. Therefore, the coexistence of the diminished serotonergic innervation of the hippocampus and the dysregulated HPA axis with the increased neurogenesis in the epileptic brain represents an apparent mechanistic conflict. The increased number of 5-HT1A receptors in dentate gyrus may shed the light on this controversy. Certainly, this increase alone was not sufficient to compensate for other endocrine, receptor, and biochemical impairments ultimately leading to depression, because the animals developed depressive behavioral deficits. The mechanisms behind this increase remain to be investigated, and it is not known whether it represents a primary cause of the enhanced neurogenesis in chronic epilepsy. For example, the increased expression of brain-derived neurotrophic factor (BDNF) and its receptor TrkB has been established in pilocarpine model of epilepsy (Kornblum et al, 1997; Schmidt-Kastner et al, 1996), and BDNF is known to promote neurogenesis (Scharfman et al, 2005). However, in the context of our findings, it is conceivable that the described increase of number of 5-HT1A receptors in dentate gyrus may protect neuronal progenitors from detrimental effects of chronic stress.

Common mechanisms shared by epilepsy and depression have been contemplated as a possible cause of high incidence of comorbidity between the two conditions (Jobe, 2003; Jobe et al, 1999; Kondziella et al, 2007). While many of our findings support such line of thought (eg the dysregulation of the HPA axis, diminished raphe-hippocampal serotonergic transmission, upregulation of presynaptic and downregulation of postsynaptic 5-HT1A receptors), the increased neuronal progenitor proliferation in the dentate gyrus under conditions of chronic epilepsy appears to be an example of divergent mechanisms underlying major depression and depression of comorbidity of epilepsy, at least in the framework of the utilized animal model. The expansion of experimental studies that would involve other experimental models and techniques would be instrumental for unveiling both overlapping and distinct mechanisms of major depression and that as a comorbidity of epilepsy. This in turn would be useful for the development of mechanism-based therapies of depression tailored to epilepsy patients.

In conclusion, we suggest that epilepsy-associated depression in the post-SE model may develop as a result of complex interaction between the dysregulated HPA axis, presynaptic 5-HT1A receptors, and the enhanced control by the latter of raphe-hippocampal serotonergic transmission. In addition, the attenuation of postsynaptic 5-HT1A receptor function in CA1 and CA3 may further exacerbate the deficiency of serotonergic ascending pathways.

\section{ACKNOWLEDGEMENTS}

This study was supported by NIH research grants R01 NS065783, R21 MH079933 and Epilepsy Foundation of America/Patricia L Nangle Fund (all to AMM), and R01 MH 52369 (to JGH).

\section{DISCLOSURE}

The authors declare no conflict of interest.

\section{REFERENCES}

Aghajanian GK, Sprouse JS, Sheldon P, Rasmussen K (1990). Electrophysiology of the central serotonin system: receptor subtypes and transducer mechanisms. Ann N Y Acad Sci 600: 93-103; discussion 103.

Bellido I, Hansson AC, Gomez-Luque AJ, Andbjer B, Agnati LF, Fuxe K (2004). Corticosterone strongly increases the affinity of dorsal raphe 5-HT1A receptors. Neuroreport 15: 1457-1459.

Bunin MA, Wightman RM (1998). Quantitative evaluation of 5-hydroxytryptamine (serotonin) neuronal release and uptake: an investigation of extrasynaptic transmission. J Neurosci 18: 4854-4860.

Cavalheiro EA, Naffah-Mazzacoratti MG, Mello LE, Leite JP (2006). The pilocarpine model of seizures. In: Pitkanen A, Schwartzkroin PA, Moshe SL (eds). Models of Seizures and Epilepsy. Elsevier: Amsterdam. pp 433-448.

Ceci A, Baschirotto A, Borsini F (1994). The inhibitory effect of 8$\mathrm{OH}-\mathrm{DPAT}$ on the firing activity of dorsal raphe serotoninergic neurons in rats is attenuated by lesion of the frontal cortex. Neuropharmacology 33: 709-713.

Chaouloff F (2000). Serotonin, stress and corticoids. J Psychopharmacol 14: 139-151.

Chaput Y, de Montigny C, Blier P (1986). Effects of a selective 5-HT reuptake blocker, citalopram, on the sensitivity of 5-HT autoreceptors: electrophysiological studies in the rat brain. Naunyn Schmiedebergs Arch Pharmacol 333: 342-348.

Clark RD (2008). Glucocorticoid receptor antagonists. Curr Top Med Chem 8: 813-838.

Connor TJ, Kelliher P, Shen Y, Harkin A, Kelly JP, Leonard BE (2000). Effect of subchronic antidepressant treatments on behavioral, neurochemical, and endocrine changes in the forced-swim test. Pharmacol Biochem Behav 65: 591-597. 
D'Ambrosio R, Hakimian S, Stewart T, Verley DR, Fender JS, Eastman CL et al (2009). Functional definition of seizure provides new insight into post-traumatic epileptogenesis. Brain 132: 2805-2821.

De Kloet ER, Sybesma H, Reul HM (1986). Selective control by corticosterone of serotonin1 receptor capacity in raphe-hippocampal system. Neuroendocrinology 42: 513-521.

Dinan T (2001). Novel approaches to the treatment of depression by modulating the hypothalamic-pituitary-adrenal axis. Hum Psychopharmacol 16: 89-93.

Djavadian RL (2004). Serotonin and neurogenesis in the hippocampal dentate gyrus of adult mammals. Acta Neurobiol Exp (Wars) 64: 189-200.

Dube C, Richichi C, Bender RA, Chung G, Litt B, Baram TZ (2006). Temporal lobe epilepsy after experimental prolonged febrile seizures: prospective analysis. Brain 129: 911-922.

Dudek FE, Bertram EH (2010). Counterpoint to 'What is epileptic seizure' by D'Ambrosio and Miller. Epilepsy Curr 10: 91-94.

Finn DP, Marti O, Harbuz MS, Valles A, Belda X, Marquez C et al (2003). Behavioral, neuroendocrine and neurochemical effects of the imidazoline $\mathrm{I} 2$ receptor selective ligand BU224 in naive rats and rats exposed to the stress of the forced swim test. Psychopharmacology (Berl) 167: 195-202.

Gould E (1999). Serotonin and hippocampal neurogenesis. Neuropsychopharmacology 21: 46S-51S.

Gould E, Tanapat P (1999). Stress and hippocampal neurogenesis. Biol Psychiatry 46: 1472-1479.

Gozlan H, Thibault S, Laporte AM, Lima L, Hamon M (1995). The selective 5-HT1A antagonist radioligand [3H]WAY 100635 labels both G-protein-coupled and free 5-HT1A receptors in rat brain membranes. Eur J Pharmacol 288: 173-186.

Gregus A, Wintink AJ, Davis AC, Kalynchuk LE (2005). Effect of repeated corticosterone injections and restraint stress on anxiety and depression-like behavior in male rats. Behav Brain Res 156: 105-114.

Hajos M, Hajos-Korcsok E, Sharp T (1999). Role of the medial prefrontal cortex in 5-HT1A receptor-induced inhibition of 5HT neuronal activity in the rat. Br J Pharmacol 126: 1741-1750.

Hensler J, Durgam H (2001). Regulation of 5-HT(1A) receptorstimulated [35S]-GtpgammaS binding as measured by quantitative autoradiography following chronic agonist administration. Br J Pharmacol 132: 605-611.

Hensler JG, Advani T, Monteggia LM (2007). Regulation of serotonin-1A receptor function in inducible brain-derived neurotrophic factor knockout mice after administration of corticosterone. Biol Psychiatry 62: 521-529.

Hensler JG, Vogt MA, Gass P (2010). Regulation of cortical and hippocampal 5-HT(1A) receptor function by corticosterone in GR+/- mice. Psychoneuroendocrinology 35: 469-474.

Heydendael W, Jacobson L (2010). Widespread hypothalamicpituitary-adrenocortical axis-relevant and mood-relevant effects of chronic fluoxetine treatment on glucocorticoid receptor gene expression in mice. Eur J Neurosci 31: 892-902.

Hokfelt T, Xu ZQ, Shi TJ, Holmberg K, Zhang X (1998). Galanin in ascending systems: focus on coexistence with 5-hydroxytryptamine and noradrenaline. Ann N Y Acad Sci 863: 252-263.

Holsboer F (1998). Current theories of the pathophysiology of mood disorders. In: Montgomery S, Halbreich U (eds). Pharmacotherapy of Mood and Cognition. American Psychiatric Press: Washington, DC.

Jackson BP, Dietz SM, Wightman RM (1995). Fast-scan cyclic voltammetry of 5-hydroxytryptamine. Anal Chem 67: 1115-1120.

Giovacchini G, Toczek MT, Bonwetsch R, Bagic A, Lang L, Fraser C et al (2005). 5-HT 1A receptors are reduced in temporal lobe epilepsy after partial-volume correction. J Nucl Med 46: 1128-1135.

Jobe PC (2003). Common pathogenic mechanisms between depression and epilepsy: an experimental perspective. Epilepsy Behav 4(Suppl 3): S14-S24.
Jobe PC, Dailey JW, Wernicke JF (1999). A noradrenergic and serotonergic hypothesis of the linkage between epilepsy and affective disorders. Crit Rev Neirobiol 13: 317-356.

Johnson SA, Fournier NM, Kalynchuk LE (2006). Effect of different doses of corticosterone on depression-like behavior and HPA axis responses to a novel stressor. Behav Brain Res 168: 280-288.

Judge SJ, Ingram CD, Gartside SE (2004). Moderate differences in circulating corticosterone alter receptor-mediated regulation of 5-hydroxytryptamine neuronal activity. J Psychopharmacol 18: 475-483.

Kanner AM (2009a). Depression and epilepsy: a review of multiple facets of their close relation. Neurol Clin 27: 865-880.

Kanner AM (2009b). Depression and epilepsy: do glucocorticoids and glutamate explain their relationship? Curr Neurol Neurosci Rep 9: 307-312.

Klink R, Robichaud M, Debonnel G (2002). Gender and gonadal status modulation of dorsal raphe nucleus serotonergic neurons. Part II. Regulatory mechanisms. Neuropharmacology 43: 1129-1138.

Kondziella D, Alvestad S, Vaaler A, Sonnewald U (2007). Which clinical and experimental data link temporal lobe epilepsy with depression? J Neurochem 103: 2136-2152.

Kornblum HI, Sankar R, Shin DH, Wasterlain CG, Gall CM (1997). Induction of brain derived neurotrophic factor mRNA by seizures in neonatal and juvenile rat brain. Mol Brain Res 44: 219-228.

LaFrance Jr WC, Kanner AM, Hermann B (2008). Psychiatric comorbidities in epilepsy. Int Rev Neurobiol 83: 347-383.

Lanfumey L, Mongeau R, Cohen-Salmon C, Hamon M (2008). Corticosteroid-serotonin interactions in the neurobiological mechanisms of stress-related disorders. Neurosci Biobehav Rev 32: 1174-1184.

Le Poul E, Laaris N, Doucet E, Laporte AM, Hamon M, Lanfumey L (1995). Early desensitization of somato-dendritic 5-HT1A autoreceptors in rats treated with fluoxetine or paroxetine. Naunyn Schmiedebergs Arch Pharmacol 352: 141-148.

Lemonde S, Turecki G, Bakish D, Du L, Hrdina PD, Bown CD et al (2003). Impaired repression at a 5-hydroxytryptamine $1 \mathrm{~A}$ receptor gene polymorphism associated with major depression and suicide. J Neurosci 23: 8788-8799.

Lothe A, Didelot A, Hammers A, Costes N, Saoud M, Gilliam F et al (2008). Comorbidity between temporal lobe epilepsy and depression: a [18F]MPPF PET study. Brain 131: 2765-2782.

Lu X, Barr AM, Kinney JW, Sanna P, Conti B, Behrens MM et al (2005). A role for galanin in antidepressant actions with a focus on the dorsal raphe nucleus. Proc Natl Acad Sci USA 102: 874-879.

Man MS, Young AH, McAllister-Williams RH (2002). Corticosterone modulation of somatodendritic 5-HT1A receptor function in mice. J Psychopharmacol 16: 245-252.

Manji HK, Drevets WC, Charney DS (2001). The cellular neurobiology of depression. Nat Med 7: 541-547.

Mann JJ, Arango V, Marzuk PM, Theccanat S, Reis DJ (1989). Evidence for the 5-HT hypothesis of suicide. A review of postmortem studies. Br J Psychiatry Suppl 7-14.

Martinez-Mota L, Contreras CM, Saavedra M (1999). Progesterone reduces immobility in rats forced to swim. Arch Med Res 30: 286-289.

Maudhuit C, Prevot E, Dangoumau L, Martin P, Hamon M, Adrien J (1997). Antidepressant treatment in helpless rats: effect on the electrophysiological activity of raphe dorsalis serotonergic neurons. Psychopharmacology (Berl) 130: 269-275.

Mazarati A, Siddarth P, Baldwin RA, Shin D, Caplan R, Sankar R (2008). Depression after status epilepticus: behavioural and biochemical deficits and effects of fluoxetine. Brain 131: 2071-2083.

Mazarati AM, Baldwin RA, Shinmei S, Sankar R (2005). In vivo interaction between serotonin and galanin receptors types 1 and 2 in the dorsal raphe: implication for limbic seizures. J Neurochem 95: 1495-1503. 
Mazarati AM, Pineda E, Shin D, Tio D, Taylor AN, Sankar R (2010). Comorbidity between epilepsy and depression: role of hippocampal interleukin-1beta. Neurobiol Dis 37: 461-467.

Mazarati AM, Shin D, Kwon YS, Bragin A, Pineda E, Tio D et al (2009). Elevated plasma corticosterone level and depressive behavior in experimental temporal lobe epilepsy. Neurobiol Dis 34: 457-461.

Oitzl MS, Fluttert M, Sutanto W, de Kloet ER (1998). Continuous blockade of brain glucocorticoid receptors facilitates spatial learning and memory in rats. Eur J Neurosci 10: 3759-3766.

Parent JM, Yu TW, Leibowitz RT, Geschwind DH, Sloviter RS, Lowenstein DH (1997). Dentate granule cell neurogenesis is increased by seizures and contributes to aberrant network reorganization in the adult rat hippocampus. J Neurosci 17: 3727-3738.

Parsey RV, Oquendo MA, Ogden RT, Olvet DM, Simpson N, Huang YY et al (2006). Altered serotonin 1A binding in major depression: a [carbonyl-C-11]WAY100635 positron emission tomography study. Biol Psychiatry 59: 106-113.

Paxinos G, Watson C (1986). The Rat Brain in Stereotaxic Coordinates. Academic Press: San Diego.

Plotsky PM, Owens MJ, Nemeroff CB (1998). Psychoneuroendocrinology of depression. Hypothalamic-pituitary-adrenal axis. Psychiatr Clin North Am 21: 293-307.

Pohorecky LA, Baumann MH, Benjamin D (2004). Effects of chronic social stress on neuroendocrine responsiveness to challenge with ethanol, dexamethasone and corticotropinreleasing hormone. Neuroendocrinology 80: 332-342.

Racine RJ (1972). Modification of seizure activity by electrical stimulation. II. Motor seizures. Electroencephalogr Clin Neurophysiol 32: 281-294.

Riad M, Garcia S, Watkins KC, Jodoin N, Doucet E, Langlois X et al (2000). Somatodendritic localization of 5-HT1A and preterminal axonal localization of 5-HT1B serotonin receptors in adult rat brain. J Comp Neurol 417: 181-194.

Robichaud M, Debonnel G (2005). Oestrogen and testosterone modulate the firing activity of dorsal raphe nucleus serotonergic neurones in both male and female rats. J Neuroendocrinol 17: 179-185.

Rossi DV, Burke TF, McCasland M, Hensler JG (2008). Serotonin$1 \mathrm{~A}$ receptor function in the dorsal raphe nucleus following chronic administration of the selective serotonin reuptake inhibitor sertraline. J Neurochem 105: 1091-1099.

Rossi DV, Valdez M, Gould GG, Hensler JG (2006). Chronic administration of venlafaxine fails to attenuate 5-HT1A receptor function at the level of receptor-G protein interaction. Int $J$ Neuropsychopharmacol 9: 393-406.

Saavedra M, Contreras CM, Azamar-Arizmendi G, HernandezLozano M (2006). Differential progesterone effects on defensive burying and forced swimming tests depending upon a gradual decrease or an abrupt suppression schedules. Pharmacol Biochem Behav 83: 130-135.

Sah R, Pritchard LM, Richtand NM, Ahlbrand R, Eaton K, Sallee FR et al (2005). Expression of the glucocorticoid-induced receptor mRNA in rat brain. Neuroscience 133: 281-292.

Sargent PA, Kjaer KH, Bench CJ, Rabiner EA, Messa C, Meyer J et al (2000). Brain serotonin1A receptor binding measured by positron emission tomography with [11C]WAY-100635: effects of depression and antidepressant treatment. Arch Gen Psychiatry 57: 174-180.

Scharfman H, Goodman J, Macleod A, Phani S, Antonelli C, Croll S (2005). Increased neurogenesis and the ectopic granule cells after intrahippocampal BDNF infusion in adult rats. Exp Neurol 192: 348-356.

Schmidt-Kastner R, Humpel C, Wetmore C, Olson L (1996). Cellular hybridization for BDNF, trkB, and NGF mRNAs and BDNF-immunoreactivity in rat forebrain after pilocarpine-induced status epilepticus. Exp Brain Res 107: 331-347.

Sprouse JS, Aghajanian GK (1987). Electrophysiological responses of serotoninergic dorsal raphe neurons to 5-HT1A and 5-HT1B agonists. Synapse 1: 3-9.

Wrona MZ, Dryhurst G (1987). Oxidation chemistry of 5hydroxytryptamine. 1. Mechanism and products formed at micromolar concentrations. J Org Chem 52: 2817-2825.

Yu S, Holsboer F, Almeida OF (2008). Neuronal actions of glucocorticoids: focus on depression. J Steroid Biochem Mol Biol 108: 300-309.

Zobel A, Wellmer J, Schulze-Rauschenbach S, Pfeiffer U, Schnell S, Elger C et al (2004). Impairment of inhibitory control of the hypothalamic pituitary adrenocortical system in epilepsy. Eur Arch Psychiatry Clin Neurosci 254: 303-311. 